Research Article

\title{
Forecasting Wind Power Generation Using Artificial Neural Network: "Pawan Danawi”—A Case Study from Sri Lanka
}

\author{
Amila T. Peiris, ${ }^{1}$ Jeevani Jayasinghe $\mathbb{D}^{1},{ }^{1}$ and Upaka Rathnayake $\mathbb{D}^{2}$ \\ ${ }^{1}$ Department of Electronics, Faculty of Applied Sciences, Wayamba University of Sri Lanka, Kuliyapitiya, Sri Lanka \\ ${ }^{2}$ Department of Civil Engineering, Faculty of Engineering, Sri Lanka Institute of Information Technology, Malabe, Sri Lanka
}

Correspondence should be addressed to Upaka Rathnayake; upakasanjeewa@gmail.com

Received 4 February 2021; Revised 7 March 2021; Accepted 17 March 2021; Published 24 March 2021

Academic Editor: François Vallée

Copyright (c) 2021 Amila T. Peiris et al. This is an open access article distributed under the Creative Commons Attribution License, which permits unrestricted use, distribution, and reproduction in any medium, provided the original work is properly cited.

\begin{abstract}
Wind power, as a renewable energy resource, has taken much attention of the energy authorities in many countries, as it is used as one of the major energy sources to satisfy the ever-increasing energy demand. However, careful attention is needed in identifying the wind power potential in a particular area due to climate changes. In this sense, forecasting both wind power generation and wind power potential is essential. This paper develops artificial neural network (ANN) models to forecast wind power generation in "Pawan Danawi", a functioning wind farm in Sri Lanka. Wind speed, wind direction, and ambient temperature of the area were used as the independent variable matrices of the developed ANN models, while the generated wind power was used as the dependent variable. The models were tested with three training algorithms, namely, Levenberg-Marquardt (LM), Scaled Conjugate Gradient (SCG), and Bayesian Regularization (BR) training algorithms. In addition, the model was calibrated for five validation percentages (5\% to $25 \%$ in $5 \%$ intervals) under each algorithm to identify the best training algorithm with the most suitable training and validation percentages. Mean squared error (MSE), coefficient of correlation $(R)$, root mean squared error ratio (RSR), Nash number, and BIAS were used to evaluate the performance of the developed ANN models. Results revealed that all three training algorithms produce acceptable predictions for the power generation in the Pawan Danawi wind farm with $R>0.91, \mathrm{MSE}<0.22$, and BIAS $<1$. Among them, the LM training algorithm at $70 \%$ of training and $5 \%$ of validation percentages produces the best forecasting results. The developed models can be effectively used in the prediction of wind power at the Pawan Danawi wind farm. In addition, the models can be used with the projected climatic scenarios in predicting the future wind power harvest. Furthermore, the models can acceptably be used in similar environmental and climatic conditions to identify the wind power potential of the area.
\end{abstract}

\section{Introduction}

The world's energy demand is ever-increasing, and related research presents numerous models to forecast future energy demand [1]. As climatic reasons and environmental conditions have forced the world to move to green energies, many countries have shown their interest in this topic by implementing new policies, rules, and laws in their communities and at least in some of the selected areas [2]. Some cities are named green cities where there is a minimum level of greenhouse gas emissions [3, 4]. Some countries have already proposed annual targets to achieve certain percentages of their energy demand by renewable energy sources. Therefore, renewable energy is a highlighted topic in the twenty-first century. Solar, wind, biomass, geothermal, hydropower, and ocean waves are some of the readily available renewable energy sources to date in the world. On average, $26.2 \%$ of the 2018 world's energy demand was supplied by renewable energies, and it is forecasted to increase the percentage up to $45 \%$ by the year 2040 [5].

Wind energy is one of the best solutions for global warming because it is completely pollution-free and causes no greenhouse effects [6]. It has become a cost-effective approach due to the rise in fossil fuel prices [7]. The wind is the only natural source of energy available everywhere and, therefore, it is the most promising renewable energy source. 
Its contribution to the world's energy demand is going to be increased in the future with the ending of the fossil fuel era [8].

Sri Lanka, as a country, is also in discussions for the generation of renewable energies, and it is proposed to generate renewable energy to meet $100 \%$ of the country's demand by 2050 [9]. However, according to the statistics of the Ceylon Electricity Board [10], as of now, the majority $(67.02 \%)$ of total electricity generation in Sri Lanka is done using thermal oil and coal followed by hydropower (30.16\%). Wind power contributes only for $2.55 \%$ of the power generation in Sri Lanka. Therefore, Sri Lanka spends thousands of million dollars to import crude oil, which is about $25 \%$ of the expenses for imports and equals $45 \%$ of income from exports [11]. On the other hand, nearly $5,000 \mathrm{~km}^{2}$ of windy areas was identified in Sri Lanka with good-to-excellent wind resource potential as reported by the Sri Lanka Sustainable Energy Authority [12].

However, the wind speed is intermittent and volatile, which makes influences on the safe operation of the power grid showing random, unstable, and antipeaking characteristics [13]. It may seriously affect the quality of electric power and the operation of the power grid. If the output of wind power generation can be accurately forecasted, the negative influences that wind power brings to the grid can be reduced by a large extent [14]. The accuracy of wind power prediction is important for balancing the power generation as well [15]. Wind power forecasting is important in ensuring the reliability of power systems and in reducing the cost of the power system too. Further, accurate predictions are helpful to the government, policymakers, and other responsible authorities for taking necessary actions.

Identifying the importance of forecasting wind power generation, researchers have applied numerous statistical, data mining, and machine learning techniques for developing prediction models [16-21]. Artificial neural network (ANN) was found to be highly popular among researchers in the field of wind power prediction. ANN was applied to assess the wind energy output of seven wind farms in Tamil $\mathrm{Nadu}$, India, using data collected over a period of 3 years [22]. Three input variables, namely, wind speed, relative humidity, and generation hours, and one output variable (i.e., the energy output of wind farms) were used for modeling in MATLAB resulting in the root mean square error (RMSE) of 0.0806 and the overall percentage error of $4 \%$. Another research based on ANN was conducted using the input parameters of average wind speed, average relative humidity, and generation hours of wind farms in Rajasthan, India [23]. The backpropagation algorithm was applied, and the mean squared error (MSE) becomes stable at 0.0070 after 300 iterations. Another ANN-based research with backpropagation was applied to develop a forecasting system for power generation in some wind fields in China [13]. According to a case study conducted in Tasmania, Australia, the prediction behavior of the ANN model is more accurate than the Similar Days approach when the performance is compared based on the daily mean absolute percentage error (MAPE) [24]. Research conducted in Prince Edward Island, Canada, concludes that ANN outperforms Fuzzy Predictor,
Adaptive Neural Fuzzy Inference System, and Committee Machines in wind power prediction [25].

The prediction of wind power generation is possible for future years if the independent variables (climatic data) are available as projected climatic variables. Related research studies are extensively carried out [26-30], and projecting future climate under different scenarios is often reported. Representative Concentration Pathway (RCP) is one such climate projection scenario [31-36] widely adopted by the Intergovernmental Panel on Climate Change (IPCC). RCP2.6, RCP4.5, RCP6.0, and RCP8.5 are four scenarios based on the greenhouse gas concentration, and the projection of various weather factors is readily available.

Forecasting the energy output of wind farms by means of short-term, medium-term, or long-term prediction is reported. Hossain et al. presented extrapolation of wind speed and apply data on adaptive neurofuzzy inference systems to develop monthly and weekly wind power density prediction models in Malaysia [37]. Metaheuristic techniques such as ant colony optimization and particle swarm optimization were also incorporated to develop forecasting models [38]. In Iran, the empirical hourly wind power output of a wind farm over a year and data of wind speed and ambient temperature were collected, and a prediction model was introduced [38]. The meteorological data consisting of wind speed and ambient temperature is used as the inputs to the mathematical model. Both the statistical and the neural network-based approaches were applied to predict hourly wind speed data of the subsequent year for long-term prediction [39].

However, to the authors' knowledge, only a few research studies have been carried out to forecast wind power in the context of Sri Lanka. Nevertheless, neural networks were used in the prediction of various energy-related research [40]. Therefore, it is highly important to carry out such a research to forecast the wind power of an already established wind farm in Sri Lanka. This will lead to understanding the importance in the context of Sri Lanka, while the results can be used for identifying the potential future wind power generations in the country. Fulfilling this research gap, the presented paper is focused on forecasting wind power generation in a wind farm in Sri Lanka: "Pawan Danawi".

\section{Methodology}

2.1. Study Area and Data Collection. This research work is done based on the "Pawan Danawi" wind farm, which is located in Kalpitiya (around $08^{\circ} 02^{\prime} 56^{\prime \prime} \mathrm{N} 79^{\circ} 43^{\prime} 08^{\prime \prime} \mathrm{E}$ ), North-Western area in Sri Lanka (Figure 1). This geographical area was identified as one of the best locations in Sri Lanka to establish a wind farm [41, 42]. It is an onshore wind farm, which has a 10.2 MW nameplate capacity with 12 wind turbines (model: Gamesa G58-850) for its operation. The height of each tower is around $65 \mathrm{~m}$, and the diameter of the blades is around $58 \mathrm{~m}$. The project was completed and connected to the national grid for its operation in August 2012.

Each wind turbine has three blades, and its rated power is $850 \mathrm{~kW}$. The generation voltage of the plant is $690 \mathrm{~V}(\mathrm{AC})$, 


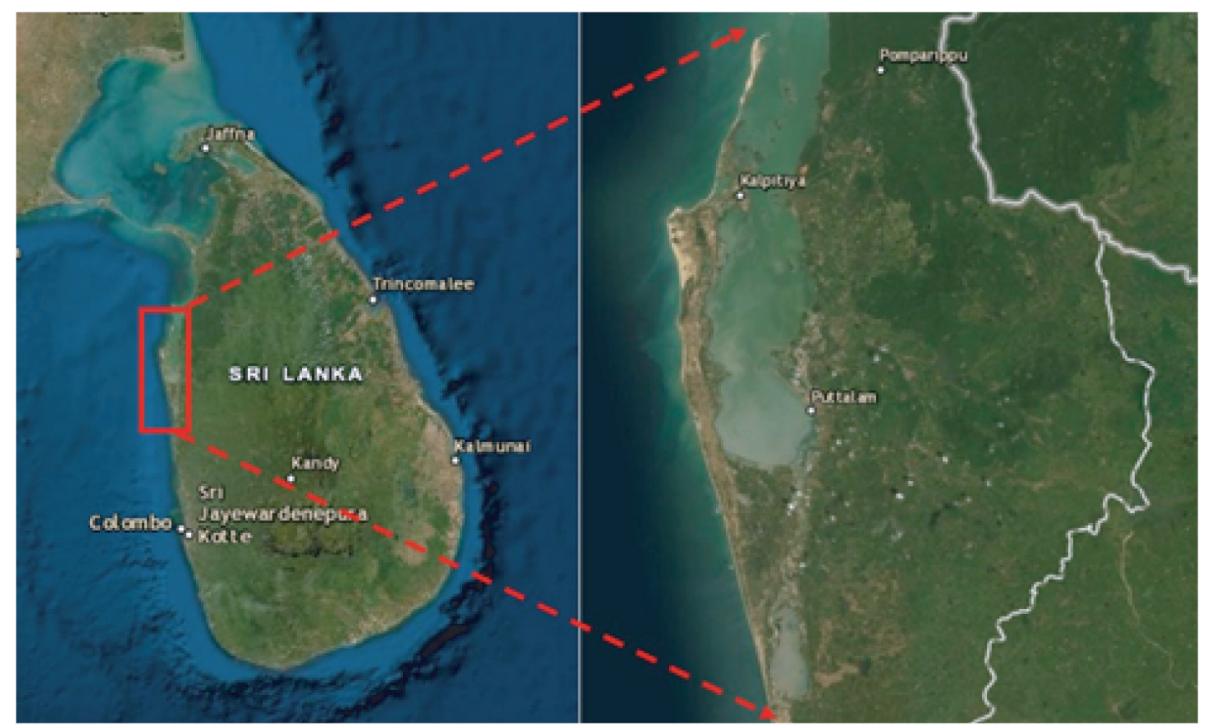

Figure 1: Study area of Pawan Danawi (image from https://earthexplorer.usgs.gov/).

and it is stepped up using a transformer to $33 \mathrm{kV}$ for connecting to the national power grid as the transmission voltage in Sri Lanka is $33 \mathrm{kV}$. The rotational speed of the rotor varies between 19.44 and $30.8 \mathrm{rpm}$, and the rated stator current at $690 \mathrm{~V}$ is $670 \mathrm{~A}$. The standard power factor at the generator output terminals at the low voltage side before transformer input terminals is 0.95 at partial loads and 1 at nominal power.

Monthly average power generation data (MW) from January 2015 to December 2019 (5 years, 60 data sets) were obtained from the wind farm authorities. Figure 2 exhibits the variation of generated power over the 5 years. The maximum power generation is around 3.0 MW. The peak power generation can be seen in the months of June, July, and August, where most of the regions in Sri Lanka receive speedy winds. The current output was also calculated assuming a unity power factor and its variation over the year 2019 is illustrated in Figure 3.

Figure 4 shows the variation of average wind speed over the months for the previous 5 years. The variation over the months in each year looks similar, and speedy winds could be observed in the months of June, July, and August.

As the peaks of both wind power generation and wind speed are visible in the same months in each year, their relationships were plotted in Figure 5 for further analysis. It indicates that power generation is exponentially correlated with wind speed. Further, most of the time, the wind speed varied between the cut-in speed and the cut-out speed of $3.0 \mathrm{~m} / \mathrm{s}$ and $20.0 \mathrm{~m} / \mathrm{s}$, respectively. The coefficient of determination obtained for the trend line of Figure 5 clearly shows that the predictive power exponentially varies with the wind power and wind speeds. However, the power generated by a wind turbine depends not only on the wind speed but also on the density of air [43]. Therefore, climate parameters of average wind speed $(\mathrm{m} / \mathrm{s})$, average wind direction $\left({ }^{\circ}\right)$, and average ambient temperature $\left({ }^{\circ} \mathrm{C}\right)$ were considered input variables in the modeling process. Their statistics were used with the average power output (MW)

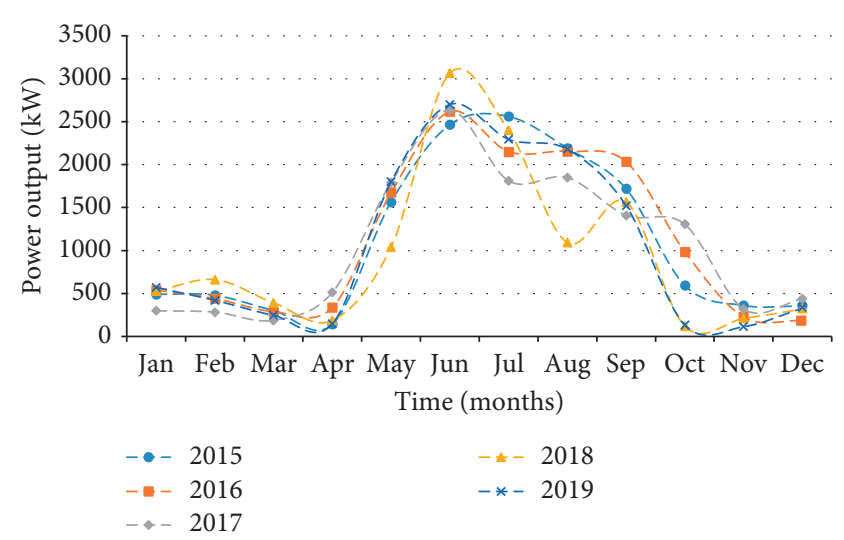

Figure 2: Variation of monthly wind power generation.

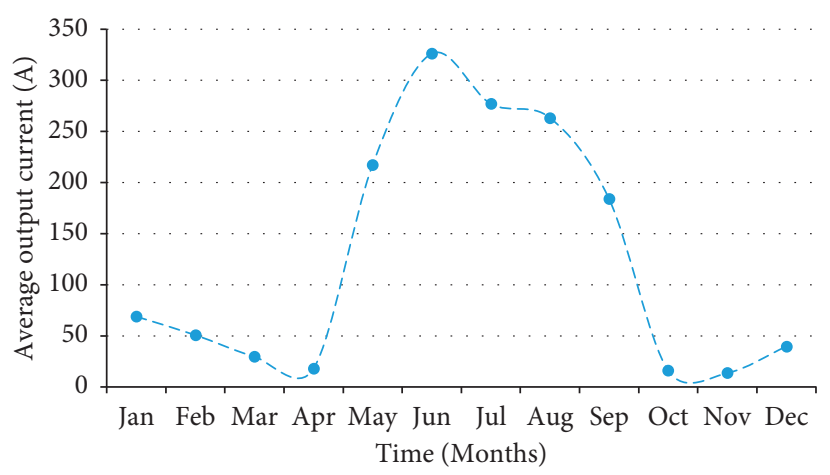

FIgURE 3: Variation of current output over the year 2019.

data in the period of January 2015 to December 2019. The monthly climatic data were collected from the wind farm, as there is an in-house meteorological station.

2.2. ANN Algorithms. A feedforward artificial neural network model was developed to predict the power generation 


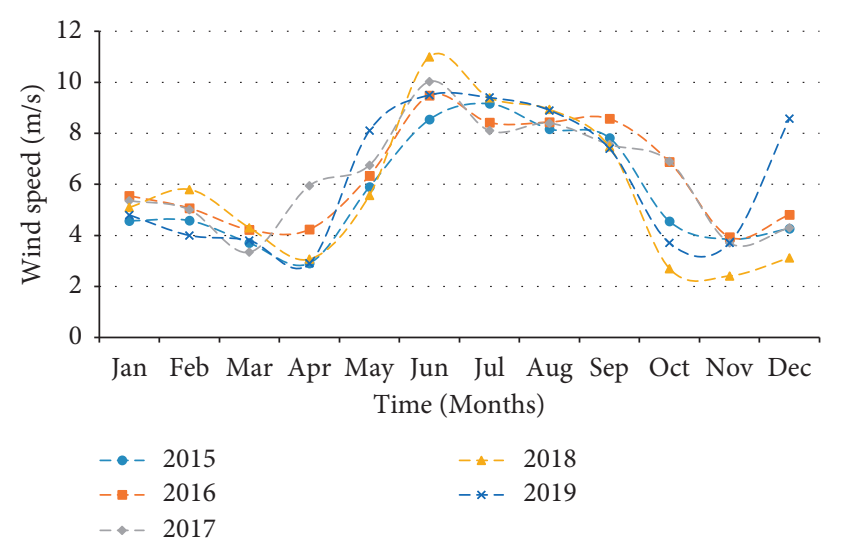

FIgURE 4: Variation of monthly wind speed.

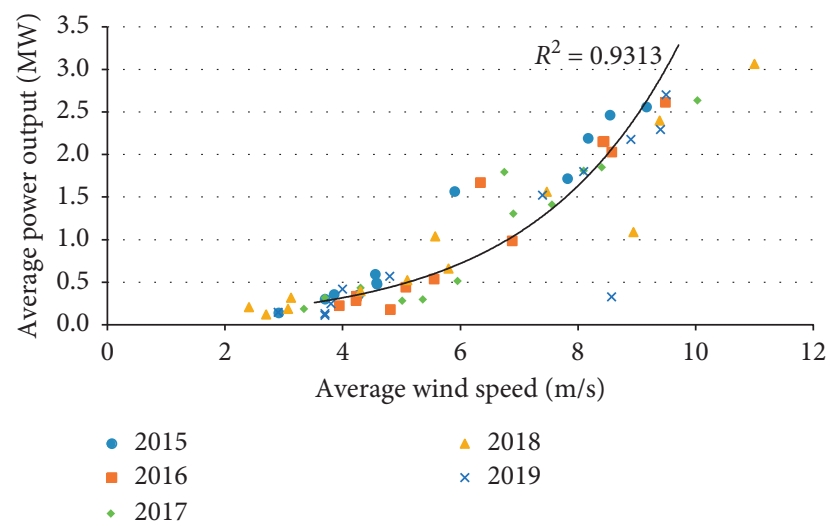

FIGURE 5: Variation of wind power generation versus average wind speed.

of the Pawan Danawi wind farm. Three frequently used algorithms, namely, Levenberg-Marquardt (LM), Scaled Conjugate Gradient (SCG), and Bayesian Regularization (BR), were applied for training data [44, 45]. LM training algorithm is a combination of the steepest descent and the Gauss-Newton method. LM includes the efficient quality of the Gauss-Newton method, which shows the backpropagation of the ANN, and the stability qualities of the steepest descent method [46]. It has been identified as an efficient and ideal algorithm for medium size networks [47] and thus widely used. However, it is not recommended for large-sized neural networks due to its memory limitations [48]. The Levenberg-Marquardt algorithm can be expressed as follows:

$$
H=J^{T} J+\mu I
$$

where $\mu$ is the combination coefficient, which is positive, $I$ is the identity matrix, and $J$ represents the Jacobian matrix. The Gauss-Newton behavior of the LM can be expressed as follows:

$$
W_{k+1}=W_{k}-\left(J_{k}^{T} \times J_{k}+\mu I\right)^{-1} \times J_{k} \times e_{k},
$$

where $W_{k+1}$ and $W_{k}$ are weights calculated using the GaussNewton method.
SCG algorithm is a combination of the conjugate gradient approach and the model trust region approach. As it has avoided the line search technique by using the trust region approach, it is a much faster technique [49]. The SCG algorithm is widely used with problems that have a higher number of linear equations. It takes fever memory and the training process stops when generalization deescalates, indicated by the increasing the mean squared error (MSE) [50].

In the BR algorithm, a conventional sum of the least square error function is combined with regularization. Therefore, it forces the neural network to converge to a set of weights and acquire minimum values for the biases, pushing the network to be smooth [51]. BR algorithm is based on the probability distribution concept. Hirschen and Schafer proposed that "test set" or "validation set" is not necessary for BR, and the complete data set can use used for model fitting and model comparison [52]. In general, this algorithm takes a little more time to train, but this is ideal for relatively smaller and difficult data sets [26].

2.3. Development of Prediction Models. The ANN models were developed based on three major climatic factors in the area, which are directly affecting the power generation. The governing equation for the model development is given in

Power $=F$ (wind speed, wind direction, ambient temperature).

MATLAB version R2014b was used to develop the ANN framework for this study. The model has three independent variable matrices as shown in equation (3) with one dependent variable matrix. To complete the nonlinear formulation and architecture of the ANN, a single hidden layer was imposed on the modeling process. Training of the ANN was performed on $70 \%$ of the data set while a calibration process was carried out to reach a better validation data percentage. The calibration process was conducted in intervals of $5 \%$ from $5 \%$ to $25 \%$. Therefore, the testing percentage of the process was automatically changed. In addition, a calibration was carried out in searching for a better training algorithm. Levenberg-Marquardt (LM), Scaled Conjugate Gradient (SCG), and Bayesian Regularization (BR) training algorithms were independently used in the training process. The process was conducted for 30 different runs for each case. In other words, $150(=5 \times 30)$ separate runs were performed for one training algorithm resulting in 450 runs in total.

The performance of the training algorithms is evaluated by widely used techniques: Mean Squared Error (MSE), Coefficient of Correlation $(R)$, and BIAS. They were determined for all three training algorithms with all five validation percentages. Root mean squared error ratio (RSR) and Nash number were also used to evaluate the performance of the ANN models. The calculation of MSE, $R, \mathrm{RSR}$, Nash number, and BIAS is given in equations (4)-(8), respectively. 


$$
\operatorname{MSE}=\frac{\sum_{i=1}^{N}\left(O_{i}-E_{i}\right)^{2}}{N},
$$

where $O_{i}$ is the observed power generation, $E_{i}$ is the expected or predicted power generation, and $N$ is the number of data points in the matrix:

$$
R=\frac{\sum_{i=1}^{N}\left(O_{i}-\bar{O}\right)\left(E_{i}-\bar{E}\right)}{\sqrt{\sum_{i=1}^{N}\left(O_{i}-\bar{O}\right)^{2} \cdot \sum\left(E_{i}-\bar{E}\right)^{2}}},
$$

where $\bar{O}$ and $\bar{E}$ are the means of observed and predicted power generations, respectively. The smaller MSE values and $R$ values closer to 1 indicate highly accurate models.

$$
\mathrm{RSR}=\frac{\sqrt{\mathrm{MSE}}}{\sigma},
$$

where $\sigma$ is the standard deviation of the observed power values.

$$
\begin{aligned}
\text { Nash number } & =1-\left[\frac{\sum_{i-1}^{N}\left(O_{i}-E_{i}\right)^{2}}{\sum_{i-1}^{N}\left(O_{i}-O_{\text {average }}\right)^{2}}\right], \\
\text { BIAS } & =\frac{\sum_{i=1}^{N}\left(E_{i}-O_{i}\right)}{N} .
\end{aligned}
$$

\section{Results and Discussion}

The results of the comparison of validation percentages (calibration of different training algorithms at various validation percentages) show that a validation percentage of $5 \%$ gives the lowest MSE at epoch 2 for the LM algorithm. At the same time, the corresponding overall $R$ value is 0.94 , which is almost equal to the results of the other four percentage values $(10 \%, 15 \%, 20 \%$, and 25\%). Figure 6 shows the variation of the predicted versus actual power for the LM algorithm at the validation percentage of $5 \%$. Overall, the LM training algorithm has successfully predicted the wind power generation according to equation (3).

Calibration of SCG training algorithm shows a better performance at validation percentage of $10 \%$ with the minimum MSE of 0.017 at epoch 21. Figure 7 shows the variation of the predicted versus actual power of the corresponding model. According to the results of SCG, there is a strong correlation between input parameters and power output at all five validation percentages.

Unlike the LM and SCG training algorithms, BR training algorithms show the best performance at $15 \%$ of validation percentage at epoch 922. However, the minimum MSE values of the BR algorithm are smaller than those of the other two algorithms and obtained at a much higher epoch. In addition, there is a strong correlation between input parameters and power output at all five validation percentages in the BR algorithm.

The performance of all models was analyzed in terms of $R$, MSE, and BIAS. The results are summarized in Table 1 . According to the results, the coefficient of correlation is higher than 0.94, MSE values are less than 0.17, and BIAS values are less than 1 , which clearly demonstrates the accuracy of the models. Furthermore, MSE values obtained in the BR-based models are smaller compared to the other two algorithms; however, they are at higher computational costs.

When considering the computational efficiency of the three algorithms, LM and SCG produce minimum MSE at relatively lesser epochs. That means LM and SCG have reached the optimum result in less time. Among them, LM has the least number of epochs. That means the performance of LM is much better. However, in the case of BR, the number of epochs that had to be run to reach the optimum result is very high. It shows that $\mathrm{BR}$ is more time-consuming than the other two algorithms to reach the optimum.

Variation of the predicted and actual power levels for the LM algorithm with a validation percentage of $15 \%$ during the past 5 years is illustrated in Figure 8. According to the results, the error is negligible in most of the months and numerically less than $0.9 \mathrm{MW}$ demonstrating the accuracy of the LM-based ANN model. As per the calculations, it exhibits an RSR of 0.524 and a Nash number of -0.723 .

Figure 8 is an interesting figure as it clearly shows the capabilities of the ANN model developed based on equation (3). In other words, the predicted power output is based on the wind speed, wind direction, and the ambient temperature of the area of interest. The prediction of wind power generation is possible for future years if the independent variables (climatic data) are available as projected climatic variables.

Therefore, the model development presented in this research is useful in predicting the future wind power generation by the Pawan Danawi wind farm. Such a model is not only useful for a particular wind farm but also highly valuable for the country itself in the path of developing renewable energy. Therefore, the developed prediction model can be considered as a starting point, and then, it can be further expanded and used across the country for forecasting the wind energy generations in future years. In addition, the model can be easily adopted by the regions and areas which have similar environmental and climatic conditions and develop the feasibility activities for future wind farms. This is highly essential in the development plans of a particular country. Similar studies conducted by other researchers based on data collected from wind farms located in other countries are summarized in Table 2. ANN and some other machine learning techniques such as support vector machine (SVM), neural network (NN), random forest $(\mathrm{RF})$, and k-nearest neighbor $(\mathrm{k}-\mathrm{NN})$ and fuzzy logic techniques were used for developing wind power prediction models. Among them, ANN reported suitable to forecast the wing power generation accurately outperforming other techniques [13, 22-25]. Statistical parameters such as mean absolute percentage error (MAPE), root mean square error (RMSE), mean absolute error (MAE), and correlation coefficient were used to assess the performance of the prediction models. In contrast, the accuracy of the proposed model was proven by using five statistical parameters. 


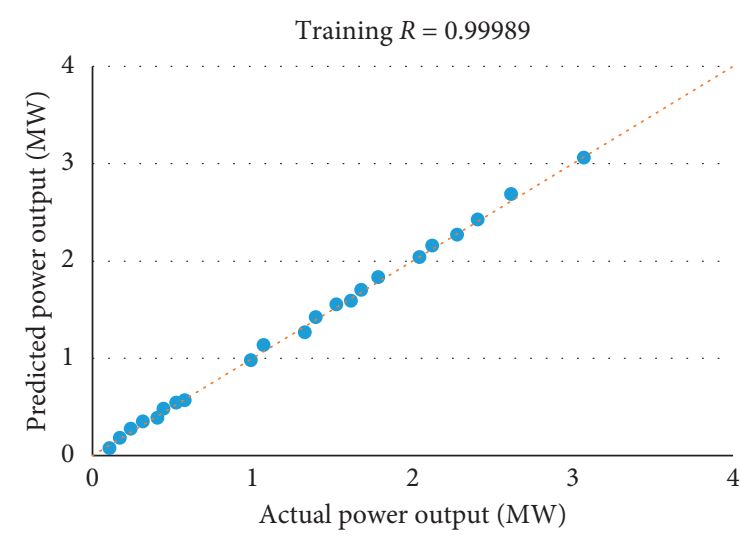

(a)

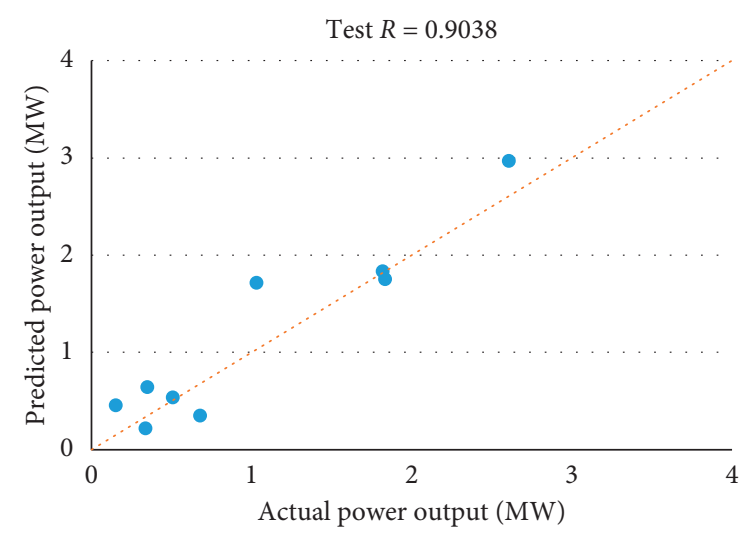

(c)

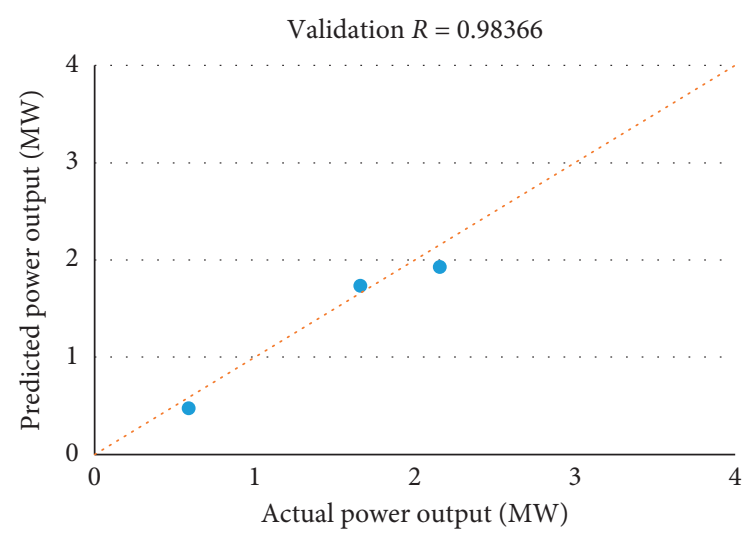

(b)

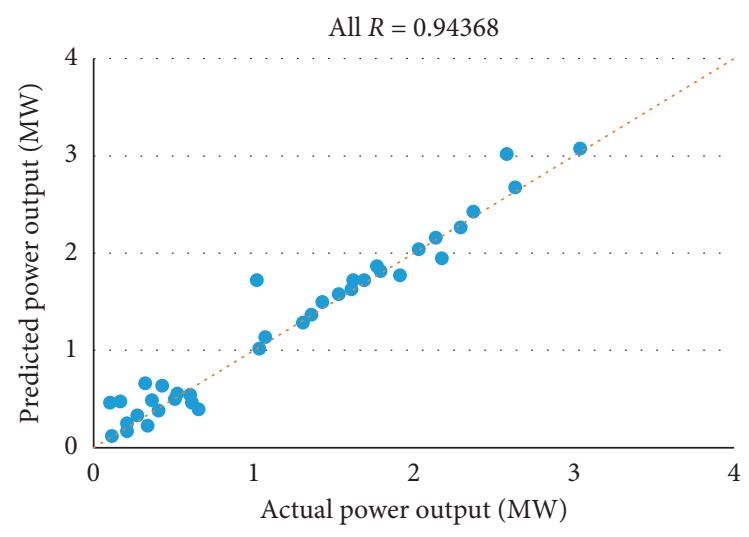

(d)

FIGURE 6: The predicted versus actual power for the LM algorithm at the validation percentage of 5\%: (a) training, (b) validation, (c) test, and (d) overall.

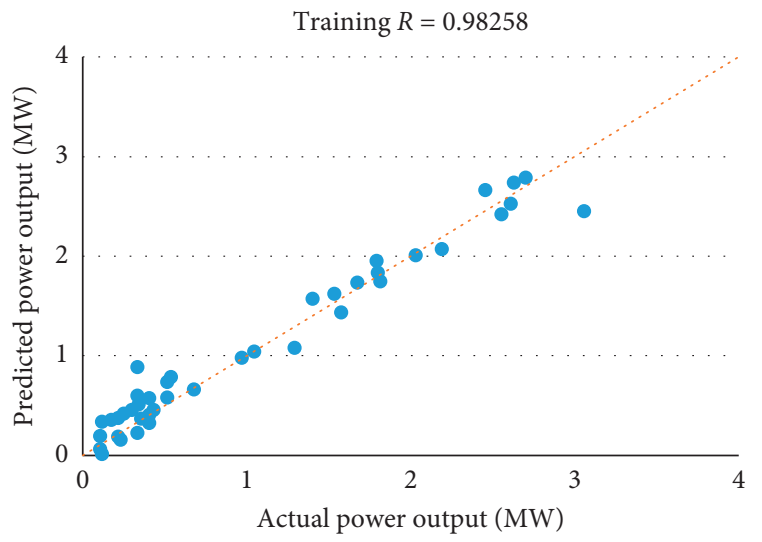

(a)

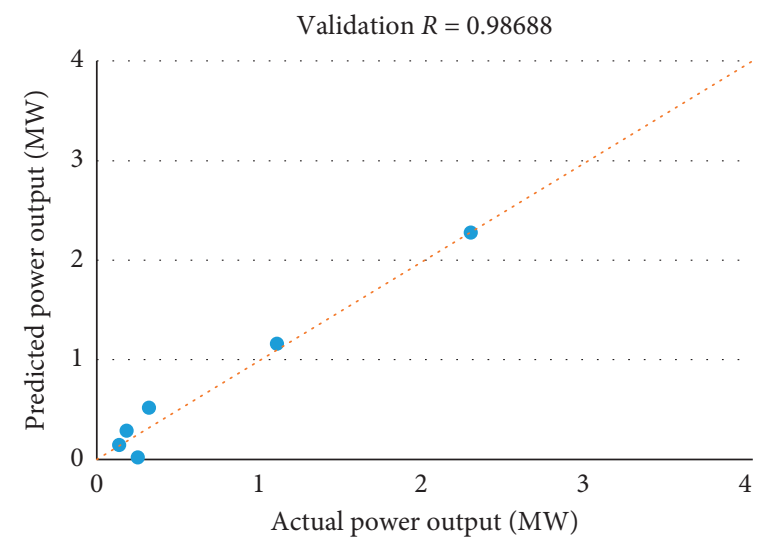

(b)

FIgURe 7: Continued. 


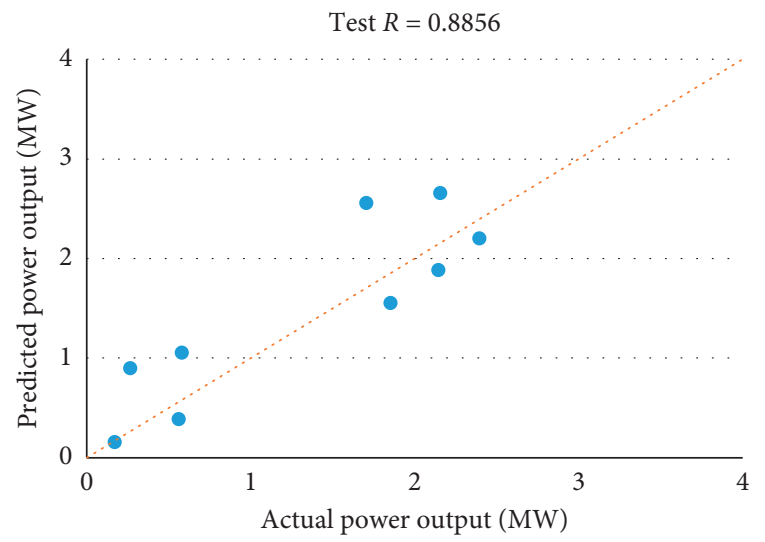

(c)

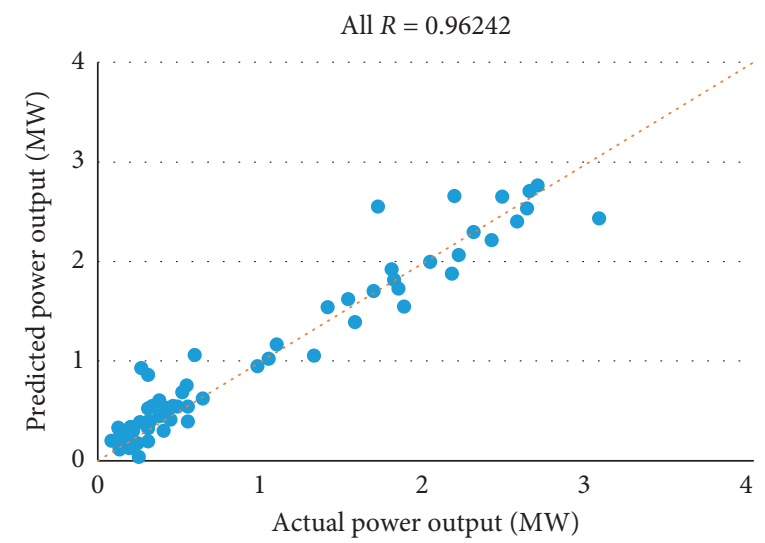

(d)

FIgURE 7: The predicted versus actual power for the SCG algorithm at the validation percentage of 10\%: (a) training, (b) validation, (c) test, and (d) overall.

TABle 1: Performance of the algorithms for different validation percentages.

\begin{tabular}{|c|c|c|c|c|c|}
\hline Validation percentage & ANN training algorithm & Number of epochs & $\mathrm{R}$ & MSE & BIAS \\
\hline \multirow{3}{*}{5} & LM & 2 & 0.94 & 0.024 & 0.078 \\
\hline & SCG & 14 & 0.95 & 0.021 & -0.027 \\
\hline & $\mathrm{BR}$ & 603 & 0.97 & 0.000 & 0.023 \\
\hline \multirow{3}{*}{10} & LM & 4 & 0.91 & 0.114 & -0.001 \\
\hline & SCG & 21 & 0.96 & 0.017 & -0.182 \\
\hline & $\mathrm{BR}$ & 314 & 0.94 & 0.006 & -0.166 \\
\hline \multirow{3}{*}{15} & LM & 2 & 0.97 & 0.219 & 0.010 \\
\hline & SCG & 19 & 0.95 & 0.163 & -0.995 \\
\hline & $\mathrm{BR}$ & 992 & 0.98 & 0.008 & -0.281 \\
\hline \multirow{3}{*}{20} & LM & 2 & 0.97 & 0.127 & 0.536 \\
\hline & SCG & 17 & 0.95 & 0.160 & 0.539 \\
\hline & $\mathrm{BR}$ & 408 & 0.99 & 0.000 & -0.276 \\
\hline \multirow{3}{*}{25} & LM & 2 & 0.97 & 0.147 & 0.522 \\
\hline & SCG & 17 & 0.94 & 0.168 & 0.708 \\
\hline & $\mathrm{BR}$ & 413 & 1.00 & 0.000 & -0.367 \\
\hline
\end{tabular}

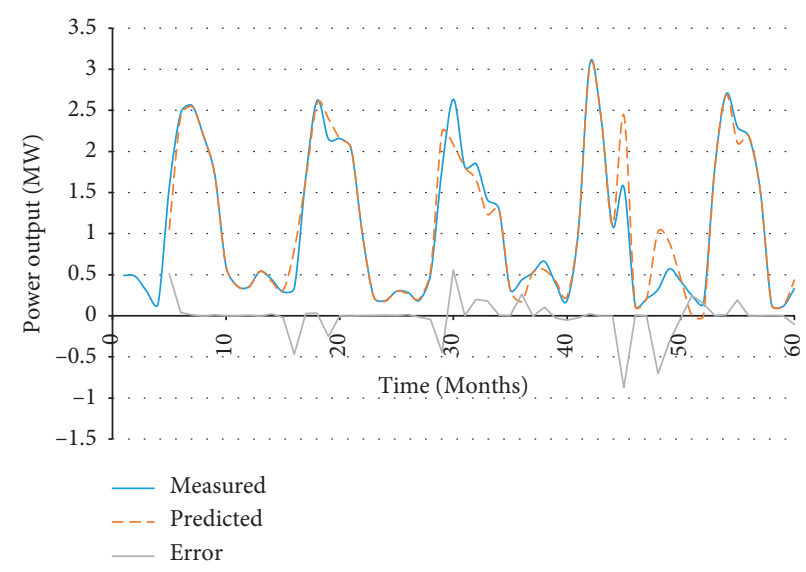

Figure 8: The error between predicted and actual power levels for LM algorithm with a validation percentage of $15 \%$. 
TABle 2: Comparison of similar research studies.

\begin{tabular}{|c|c|c|c|c|}
\hline Ref. & Techniques used & Location & Independent variables & Performance evaluation \\
\hline [13] & $\begin{array}{l}\text { ANN with BP neural } \\
\text { network }\end{array}$ & China & Wind velocity and wind direction & Error \\
\hline$[14]$ & $\begin{array}{l}\text { ANN with BP neural } \\
\text { network }\end{array}$ & - & $\begin{array}{c}\text { Wind speed, maximum, minimum, and average } \\
\text { temperature, average humidity, air pressure, and } \\
\text { rainfall }\end{array}$ & MAPE and RMSE \\
\hline [15] & $\begin{array}{l}\text { Recursive least squares } \\
\text { algorithm }\end{array}$ & Sri Lanka & Wind speed & RMSE \\
\hline [16] & SVM, NN), RF and k-NN & $\begin{array}{l}\text { Gansu } \\
\text { province, } \\
\text { China }\end{array}$ & $\begin{array}{c}\text { Temperature, wind speed, wind direction, cloud } \\
\text { cover, pressure, heat flux, radiation, precipitation, } \\
\text { humidity, etc. }\end{array}$ & MAE, MAPE, RMSE \\
\hline [17] & $\begin{array}{l}\text { Wavelet method and the } \\
\text { improved time series } \\
\text { method }\end{array}$ & China & Wind speed & MAE, MAPE, MSE \\
\hline$[18]$ & $\begin{array}{l}\text { Multilayer perceptron } \\
\text { network and integrated k- } \\
\text { NN }\end{array}$ & - & $\begin{array}{l}\text { Wind speed, wind direction, air density, } \\
\text { temperature difference, sensible heat flux, and } \\
\text { vegetation }\end{array}$ & $\begin{array}{l}\text { MAE and standard deviation of } \\
\text { absolute error }\end{array}$ \\
\hline [19] & ANN & Portugal & Wind speed & $\begin{array}{c}\text { MAE, RMSE and mean relative } \\
\text { error }\end{array}$ \\
\hline$[21]$ & $\begin{array}{l}\text { Neural networks and fuzzy } \\
\text { logic techniques }\end{array}$ & $\begin{array}{l}\text { Aalborg, } \\
\text { Denmark }\end{array}$ & Wind speed, wind direction, temperature & $\begin{array}{c}\text { Normalize mean absolute error, } \\
\text { normalized root mean square } \\
\text { error }\end{array}$ \\
\hline$[22]$ & ANN & $\begin{array}{l}\text { Tamil Nadu, } \\
\text { India }\end{array}$ & $\begin{array}{l}\text { Wind speed, relative humidity, and generation } \\
\text { hours }\end{array}$ & RMSE and MAE \\
\hline$[23]$ & $\begin{array}{l}\text { ANN with BP neural } \\
\text { network }\end{array}$ & $\begin{array}{l}\text { Rajasthan, } \\
\text { India }\end{array}$ & $\begin{array}{c}\text { Generation hours, relative humidity, and wind } \\
\text { speed }\end{array}$ & MSE and MAE \\
\hline$[25]$ & $\begin{array}{l}\text { ANN and radial basis } \\
\text { function neural networks }\end{array}$ & Canada & $\begin{array}{l}\text { Temperature, dew point temperature, relative } \\
\text { humidity, wind direction, wind speed, pressure }\end{array}$ & $\begin{array}{l}\text { MSE, absolute mean error, } \\
\text { MAPE, and correlation } \\
\text { coefficient }\end{array}$ \\
\hline
\end{tabular}

\section{Conclusions}

Forecasting models based on the artificial neural network were developed to predict the wind power generation of Pawan Danawi wind farm in Sri Lanka. The results showcased the capabilities and robustness of the prediction models developed under various training algorithms in which the Levenberg-Marquardt (LM) algorithm with a validation percentage of $15 \%$ produced the best results. Therefore, the LM-based ANN model is proposed to predict the potential wind power generation with the help of projected climatic scenarios in future years. Accordingly, the results of the research open a new era for the wind power generations in Sri Lanka to plan its energy demand and supply in the future. Sri Lanka, as a developing country, can effectively use this development to achieve its sustainable goals in renewable energy generation at a low cost. In addition, the results can effectively be used in similar climatic areas in the country to showcase the feasibility of wind power potential and its economic worth. However, research expansions are proposed with more data probably from the Kalpitiya area as the establishment of few more wind farms is in progress.

\section{Data Availability}

Prior request from Lanka Transformers Limited is needed for the availability of power generation data and climatic data.

\section{Conflicts of Interest}

The authors declare that they have no conflicts of interest.

\section{Acknowledgments}

The authors are thankful to Lanka Transformers Limited (LTL Holdings) for providing climate data.

\section{References}

[1] I. Ghalehkhondabi, E. Ardjmand, G. R. Weckman, and W. A. Young, "An overview of energy demand forecasting methods published in 2005-2015," Energy Systems, vol. 8, no. 2, pp. 411-447, 2017.

[2] Z. Abdmouleh, R. A. M. Alammari, and A. Gastli, "Review of policies encouraging renewable energy integration \& best practices," Renewable and Sustainable Energy Reviews, vol. 45, pp. 249-262, 2015.

[3] P. W. Newton and B. C. Rogers, "Transforming built environments: towards carbon neutral and blue-green cities," Sustainability, vol. 12, no. 11, p. 4745, 2020.

[4] B. Shabandri, S. R. Madara, and P. Maheshwari, "IoT-based smart tree management solution for green cities," Internet of Things and Analytics for Agriculture, vol. 2, pp. 181-199, 2020.

[5] https://www.c2es.org/content/renewable-energy.

[6] A. K. Mishra and L. Ramesh, "Application of neural networks in wind power (generation) prediction," in Proceedings of the 2009 International Conference on Sustainable Power Generation and Supply, pp. 1-5, IEEE, Nanjing, China, April 2009. 
[7] A. Bilal Awan and Z. Ali Khan, "Recent progress in renewable energy - remedy of energy crisis in Pakistan," Renewable and Sustainable Energy Reviews, vol. 33, pp. 236-253, 2014.

[8] Y. Zhang and K. W. Chan, The Impact of Wind Forecasting in Power System Reliability, DRPT2008, IntechOpen, Nanjing China, 2008.

[9] 2017 Sri Lanka on Path to 100\% Renewable Energy Says a New Joint Report by UNDP and ADB, https://www.undp.org.

[10] 2020 Ceylon Electricity Board website, on 23/08/2020 https:// www.ceb.lk/.

[11] R. H. S. Samaratunga, "Sri lanka's petroleum industry: policy, organization and challenges," 2014.

[12] Sri Lanka Sustainable Energy Authority, http://www.energy. gov.lk/en/renewable-energy/technologies/wind-power, 2020.

[13] M. Zhang, H. Xu, J. Xu, and T. Yun, "Study on application of the forecasting system for wind farm power," in Proceedings of the 2010 2nd International Conference on Signal Processing Systems, pp. 198-201, IEEE, Dalian, China, July 2010.

[14] S. Guo, Y. Li, and S. Xiao, "Wind speed forecasting of genetic neural model based on rough set theory," in Proceedings of the 2010 5th International Conference on Critical Infrastructure (CRIS), Beijing, China, September 2010.

[15] M. Narayana and S. Witharana, "Adaptive prediction of power fluctuations from a wind turbine at Kalpitiya area in Sri Lanka," in Proceedings of the 2012 IEEE 6th International Conference on Information and Automation for Sustainability, IEEE, Beijing, China, September 2012.

[16] T. Ouyang, X. Zha, and L. Qin, “A combined multivariate model for wind power prediction," Energy Conversion and Management, vol. 144, pp. 361-373, 2017.

[17] H. Liu, H.-Q. Tian, C. Chen, and Y.-f. Li, "A hybrid statistical method to predict wind speed and wind power," Renewable Energy, vol. 35, no. 8, pp. 1857-1861, 2010.

[18] A. Kusiak, H. Zheng, and Z. Song, "Wind farm power prediction: a data-mining approach," Wind Energy, vol. 12, no. 3, pp. 275-293, 2009.

[19] P. Gomes and R. Castro, "Wind speed and wind power forecasting using statistical models: autoregressive moving average (ARMA) and artificial neural networks (ANN)," International Journal of Sustainable Energy Development, vol. 1, p. 1/2, 2012.

[20] X. Zhao, S. Wang, and T. Li, "Review of evaluation criteria and main methods of wind power forecasting," Energy Procedia, vol. 12, pp. 761-769, 2011.

[21] G. Sideratos and N. D. Hatziargyriou, "An advanced statistical method for wind power forecasting," IEEE Transactions on Power Systems, vol. 22, no. 1, pp. 258-265, 2007.

[22] M. C. Mabel and E. Fernandez., "Analysis of wind power generation and prediction using ANN: a case study," Renewable Energy, vol. 33, no. 5, pp. 986-992, 2008.

[23] V. Singh, "Application of artificial neural networks for predicting generated wind power," International Journal of Advanced Computer Science and Applications, vol. 7, 2016.

[24] M. Negnevitsky, P. Mandal, and A. K. Srivastava, "Machine learning applications for load, price and wind power prediction in power systems," in Proceedings of the 2009 15th International Conference on Intelligent System Applications to Power Systems, pp. 1-6, IEEE, Curitiba, Brazil, November 2009.

[25] A. K. Choudhary, K. G. Upadhyay, and M. M. Tripathi, "Soft computing applications in wind speed and power prediction for wind energy," in Proceedings of the 2012 IEEE Fifth Power India Conference, pp. 1-6, IEEE, Murthal, Haryana, India, December 2012.
[26] R. Gençay and M. Min Qi, "Pricing and hedging derivative securities with neural networks: bayesian regularization, early stopping, and bagging," IEEE Transactions on Neural Networks, vol. 12, no. 4, pp. 726-734, 2001.

[27] R. Goody, J. Anderson, and G. North, "Testing climate models: an approach," Bulletin of the American Meteorological Society, vol. 79, no. 11, pp. 2541-2549, 1998.

[28] E. P. Maurer, B. Levi, T. Pruitt, and P. B. Duffy, "Fine-resolution climate projections enhance regional climate change impact studies," 2007.

[29] J. Morim, M. Hemer, X. L. Wang et al., "Robustness and uncertainties in global multivariate wind-wave climate projections," Nature Climate Change, vol. 9, no. 9, pp. 711-718, 2019.

[30] L. Zhao, O. Keith, E. Bou-Zeid et al., "Global multi-model projections of local urban climates," Nature Climate Change, vol. 11, pp. 1-6, 2021.

[31] Z. Zheng, H. Cai, Z. Wang, and X. Wang, "Simulation of climate change impacts on phenology and production of winter wheat in northwestern China using CERES-wheat model," Atmosphere, vol. 11, no. 7, p. 681, 2020.

[32] L. Nazarenko, G. A. Schmidt, R. L. Miller et al., "Future climate change under RCP emission scenarios with GISS M odelE2," Journal of Advances in Modeling Earth Systems, vol. 7, no. 1, pp. 244-267, 2015.

[33] R. San José, J. L. Pérez, R. M. González, J. Pecci, A. Garzón, and M. Palacios, "Impacts of the 4.5 and 8.5 RCP global climate scenarios on urban meteorology and air quality: application to Madrid, Antwerp, Milan, Helsinki and London," Journal of Computational and Applied Mathematics, vol. 293, pp. 192-207, 2016.

[34] M. Meinshausen, S. J. Smith, K. Calvin et al., "The RCP greenhouse gas concentrations and their extensions from 1765 to 2300," Climatic Change, vol. 109, no. 1-2, pp. 213-241, 2011.

[35] D. P. Van Vuuren, J. Edmonds, M. Kainuma et al., "The representative concentration pathways: an overview," Climatic Change, vol. 109, no. 1-2, pp. 5-31, 2011.

[36] C. Karunanayake and B. Miyuru, "Inflow forecast of iranamadu reservoir, Sri Lanka, under projected climate scenarios using artificial neural networks," Applied Computational Intelligence and Soft Computing, vol. 2020, Article ID 8821627, 11 pages, 2020.

[37] M. Hossain, S. Mekhilef, F. Afifi et al., "Application of the hybrid ANFIS models for long term wind power density prediction with extrapolation capability," PloS One, vol. 13, no. 4, Article ID e0193772, 2018.

[38] R. Rahmani, R. Yusof, M. Seyedmahmoudian, and S. Mekhilef, "Hybrid technique of ant colony and particle swarm optimization for short term wind energy forecasting," Journal of Wind Engineering and Industrial Aerodynamics, vol. 123, pp. 163-170, 2013.

[39] H. B. Azad, S. Mekhilef, and V. G. Ganapathy, "Long-term wind speed forecasting and general pattern recognition using neural networks," IEEE Transactions on Sustainable Energy, vol. 5, no. 2, pp. 546-553, 2014.

[40] B. Khaniya, C. Karunanayake, and B. Miyuru, "Projection of future hydropower generation in samanalawewa power plant, Sri Lanka," Mathematical Problems in Engineering, vol. 2020, Article ID 8862067, 11 pages, 2020.

[41] A. G. Amarasinghe and E. N. C. Perera, "Modeling predictive suitability to determine potential areas for establishing wind power plants in Sri Lanka," Modeling Earth Systems and Environment, vol. 7, no. 14, pp. 1-12, 2020. 
[42] M. Narayana, "Validation of wind resource assessment model (WRAM) map of Sri Lanka, using measured data, and evaluation of wind power generation potential in the country," Energy for Sustainable Development, vol. 12, no. 1, pp. $64-68,2008$.

[43] A. S. Ahmed, "Technical and economic feasibility of the first wind farm on the coast of Mediterranean Sea," Ain Shams Engineering Journal, vol. 19, 2021.

[44] M. Kayri, "Predictive abilities of bayesian regularization and Levenberg-Marquardt algorithms in artificial neural networks: a comparative empirical study on social data," Mathematical and Computational Applications, vol. 212 pages, 2016.

[45] A. Aich, D. Amit, and A. Chakraborty, A Scaled Conjugate Gradient Backpropagation Algorithm for Keyword Extraction. In Information Systems Design and Intelligent Applications, pp. 674-684, Springer, Singapore, Singapore, 2018.

[46] S. Mishra, R. Prusty, and P. Kumar Hota, "Analysis of Levenberg-Marquardt and Scaled Conjugate gradient training algorithms for artificial neural network based LS and MMSE estimated channel equalizers," in Proceedings of the 2015 International Conference on Man and Machine Interfacing (MAMI), pp. 1-7, IEEE, Bhubaneswar, Odisha, December 2015.

[47] H. Liu, "On the Levenberg-Marquardt training method for feed-forward neural networks," vol. 1, pp. 456-460, in Proceedings of the 2010 sixth international conference on natural computation, vol. 1, pp. 456-460, IEEE, Yantai, China, August 2010.

[48] B. M. Wilamowski, Y. Chen, and A. Malinowski., "Efficient algorithm for training neural networks with one hidden layer," vol. 3, pp. 1725-1728, in Proceedings of the IJCNN'99. International Joint Conference on Neural Networks. Proceedings (Cat. No. 99CH36339), vol. 3, pp. 1725-1728, IEEE, Washington, DC, USA, July 1999.

[49] B. Cetişli and A. Barkana, "Speeding up the scaled conjugate gradient algorithm and its application in neuro-fuzzy classifier training," Soft Computing, vol. 14, no. 4, p. 365, 2010.

[50] Møller and M. Fodslette, "A scaled conjugate gradient algorithm for fast supervised learning," Neural Networks, vol. 6, no. 4, pp. 525-533, 1993.

[51] L. M. Saini, "Peak load forecasting using Bayesian regularization, Resilient and adaptive backpropagation learning based artificial neural networks," Electric Power Systems Research, vol. 78, no. 7, pp. 1302-1310, 2008.

[52] K. Hirschen and M. Schäfer, "Bayesian regularization neural networks for optimizing fluid flow processes," Computer Methods in Applied Mechanics and Engineering, vol. 195, no. 7-8, pp. 481-500, 2006. 